\title{
BER Performance of Digital Modulation Schemes With and Without OFDM Model for AWGN, Rayleigh and Rician Channels
}

\author{
Usha S. M., Dr. K. R. Nataraj ${ }^{2}$ \\ ${ }^{1}$ Asst Prof, ECE Dept, JSS ATE, Bangaluru, Research Scholar, VTU Belgaum, \\ ${ }^{2}$ Prof and HoD, ECE Dept, SJBIT, Bangaluru
}

\begin{abstract}
OFDM is an Orthogonal Frequency Division Multiplexing. It is a multiplexing technique based on parallel transmission. OFDM is used in many of the present day wireless communication techniques. It is a digital modulation scheme and is used for encoding the digital data on multiple carrier frequencies. Each subcarrier is modulated using different modulation techniques. In the first part this paper the BER performance of all digital communication techniques on AWGN, Rayleigh and rician channels are studied and compared. In the second part the performance OFDM paired with different modulation schemes are analyzed for AWGN channel.
\end{abstract}

Keywords: BER, OFDM, AWGN, Rayleigh, Racian, QPSK, QAM, DPSK, OOFDM

\section{Introduction}

Health has become a serious issue. Analysis of health monitoring devices highly depends on the efficiency of the network systems. Health can be monitored on personal devices like mobile phone computer. This requires efficient transmission. Thus selection transmitter is crucial. Transmitter efficiency is measured in terms of BER or PER. Goals of digital communication systems to have least probability error and effective channel bandwidth.

\section{Fading Channels}

Fading is the distortion experienced by carrier modulated digital signal as it travels certain path. The multipath induced fading is most common in multipath propagation. The small scale fadings are Rayleigh, Rician and Nakagami. Additive white guassian noise (AWGN), is a simplest noise that any signal can get.

$\mathrm{r}(\mathrm{t})=\mathrm{s}(\mathrm{t})+\mathrm{n}(\mathrm{t})$ where

$\mathrm{s}(\mathrm{t})=\operatorname{Re}\left\{\mathrm{u}(\mathrm{t}) \mathrm{e}^{\mathrm{j} 2 \pi \mathrm{fct}}\right\}$ and $\mathrm{n}(\mathrm{t})$ is AWGN.

Guassian PDF of AWGN is given by $\mathrm{p}(\mathrm{x})=1 / \sqrt{ }\left(2 \pi \Gamma^{2}\right)$

$\mathrm{e}^{-(\mathrm{x}-\mu) 2}$ With $\mathrm{u}=0$ and $\Gamma^{2}=\mathrm{N}_{0} / 2$

Rayleigh fading channel is the sum of the all the scattered signals received from many paths at the receiver and the reflected signals. It is used for modeling signals of ionosphere and troposphere. In urban environment this model is used for modeling various radio signals. Let us consider $\mathrm{y}=\mathrm{x}_{1}{ }^{2}+\mathrm{x}_{2}{ }^{2}$ Gaussian PDF of Rayleigh fading channel is given by $\operatorname{Py}(y)=1 / 2 \Gamma^{2}$.

Rician fading channel, scattered signals from different paths are received, one of the signal changesshortening/lenghthing. Unlike Rayleigh fadinding channel, the racian channel is non-chi square centric. Consider the $\mathrm{s} 2=\mathrm{m}_{12}+\mathrm{m}_{22}$, Gaussian PDF of rician fading channel is given by $_{8} \operatorname{Py}(\mathrm{y})=\mathrm{r} / 2 \Gamma^{2} \mathrm{e}^{-(\mathrm{s} 2+\mathrm{y}) / 2 \Gamma 2)} \mathrm{I}_{0}\left(\sqrt{ }(\mathrm{y}) \mathrm{s} / \Gamma^{2}\right)$

\section{Digital Modulation Schemes}

Various modulation schemes are explained below

\subsection{BPSK Transmitter and Receiver}

Simplest form of PSK and it also known as Phase reversal keying or 2-PSK. Phases are separated by $180^{\circ} . \sqrt{ }$ the maximum rate of modulation is $1 \mathrm{bit} / \mathrm{symbol}$.

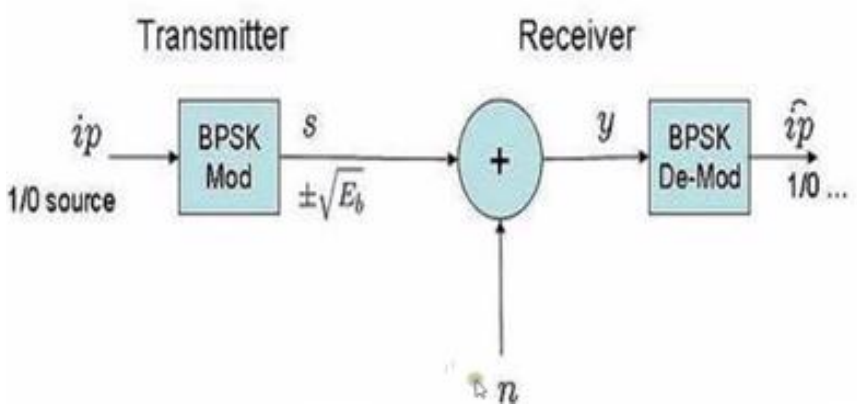

Figure 1: Block diagram of BPSK system

\subsection{QAM Modulation}

QAM supports both analog and digital modulation schemes, it transmits two message signals by changing the amplitude of the carrier signal.

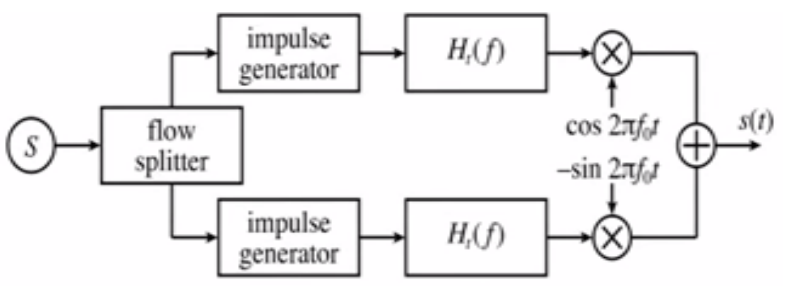

Figure 2: Block diagram of QAM Modulation

Carrier signals have phase difference of 180 hence the name quadrature. The final QAM output waveform is the sum of 


\section{International Journal of Science and Research (IJSR) \\ ISSN (Online): 2319-7064 \\ Index Copernicus Value (2013): 6.14 | Impact Factor (2014): 5.611}

PSK and ASK digital system and the sum of PM and AM form the analog system.

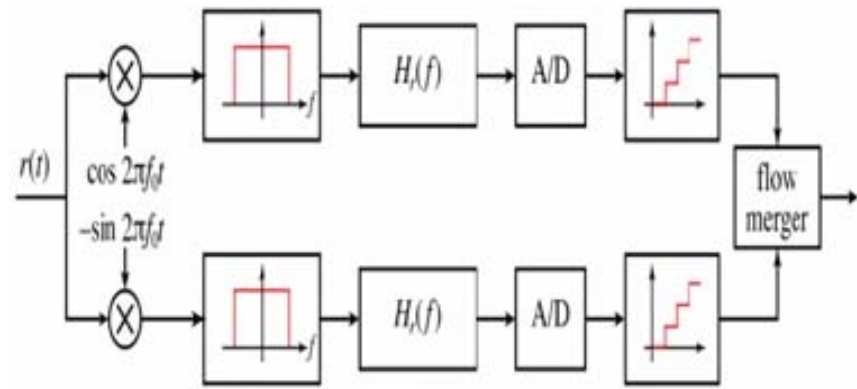

Figure 3: Block diagram of QAM demodulation

\subsection{FSK, PSK, DPSK, OQPSK and PAM Modulation}

The signal transmitted by frequency modulation of the carrier signal. It is also called as binary FSK.PSK is the modulation of the phase of the signal. The constellation point are placed around the circle at a uniform angle. When the demodulator doesn't have the original signal to compare against, it is prone to erroneous modulation. The difference in the phase of the received signal is the differential phase shift keying. One of the PSK variants uses four phases of the signal to transmit odd and even bits are offset by 1 bit period. The pulse amplitude modulation (PAM) is an analog modulation Technique.

\section{Simulation and Results}

$\left\{d_{k}\right\}$

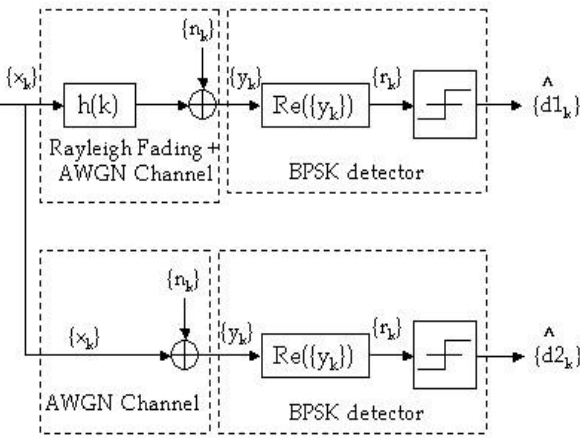

Figure 4: BPSK modulator in Rayleigh and AWGN channel

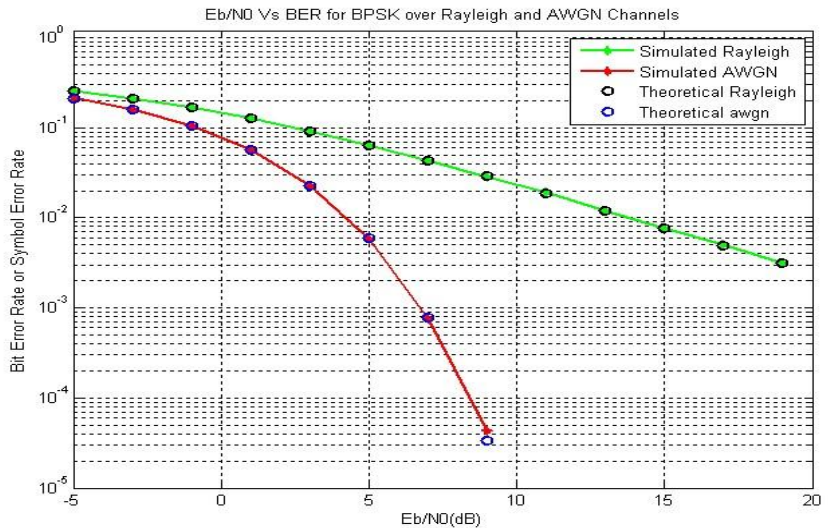

Figure 5: Eb/No Vs BER for BPSK over Rayleigh and AWGN Channels

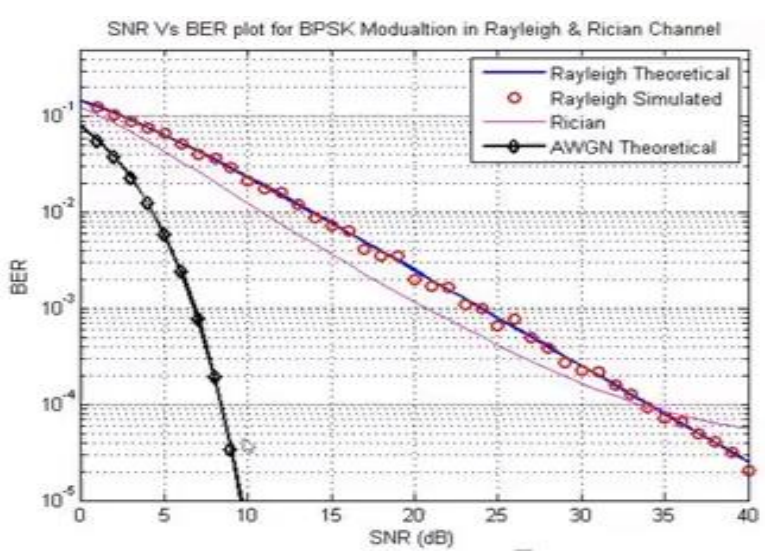

Figure 6: SNR Vs BER for BPSK over Rayleigh and AWGN Channels

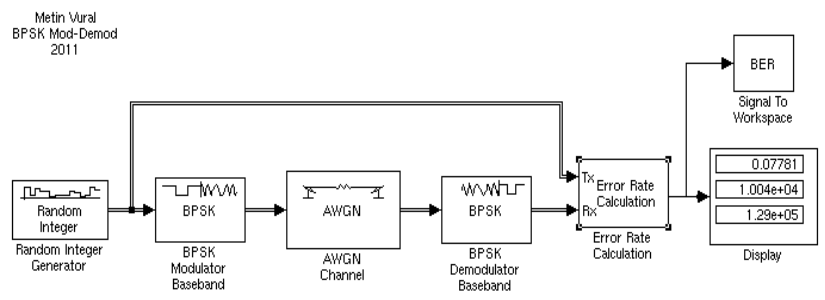

Figure 7: Block diagram of BPSK system using Simulink

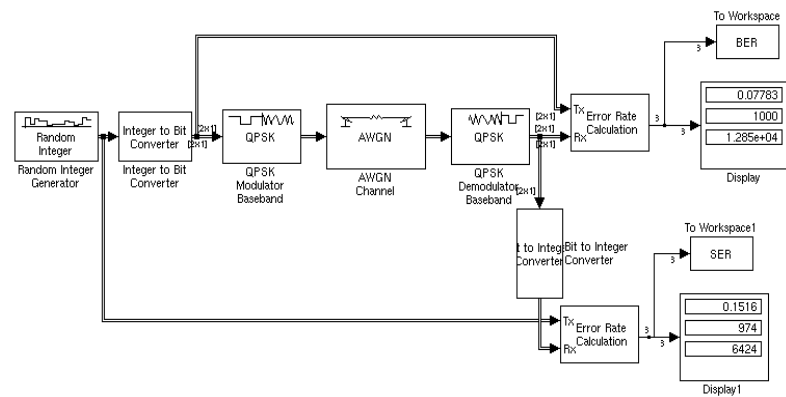

Figure 8: Block diagram of QPSK system using Simulink

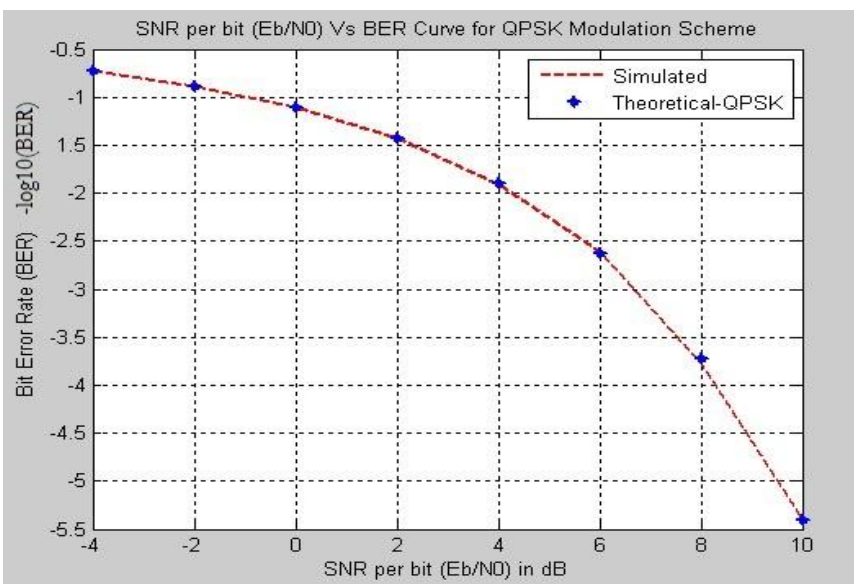

Figure 9: SNR per bit (Eb/No) Vs BER curve for QPSK modulation scheme 


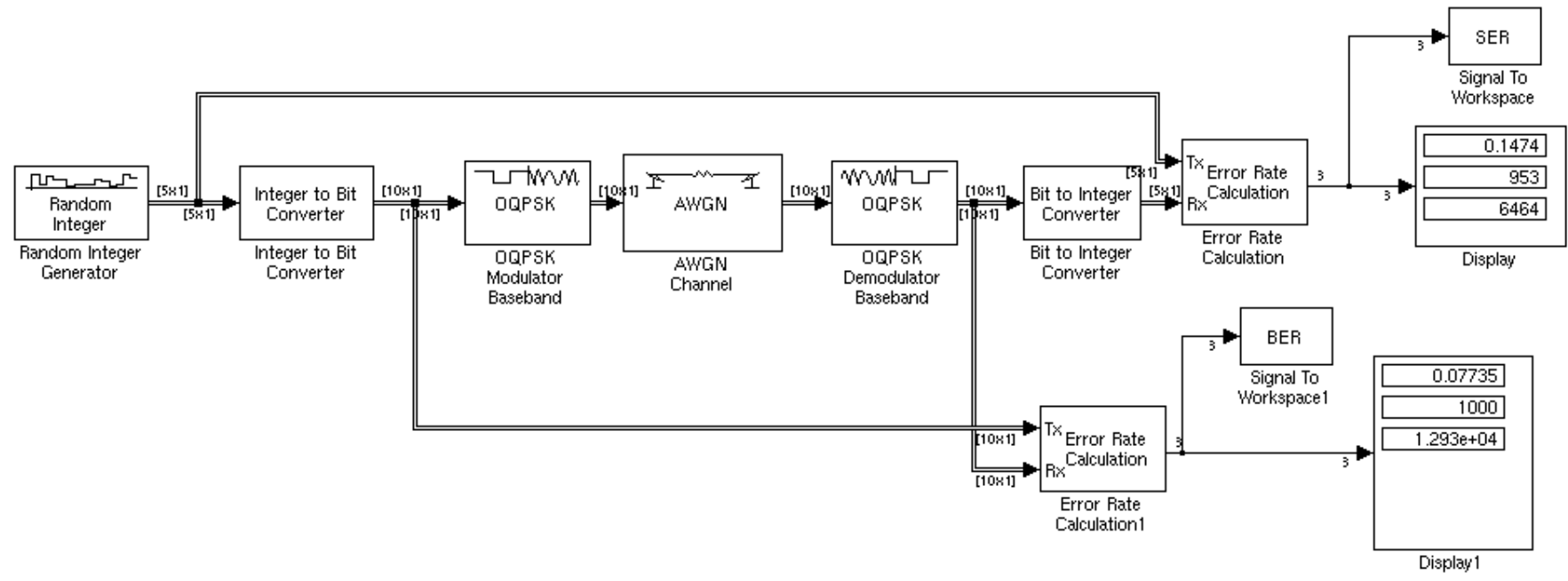

Figure 10: Block diagram of OQPSK system using Simulink

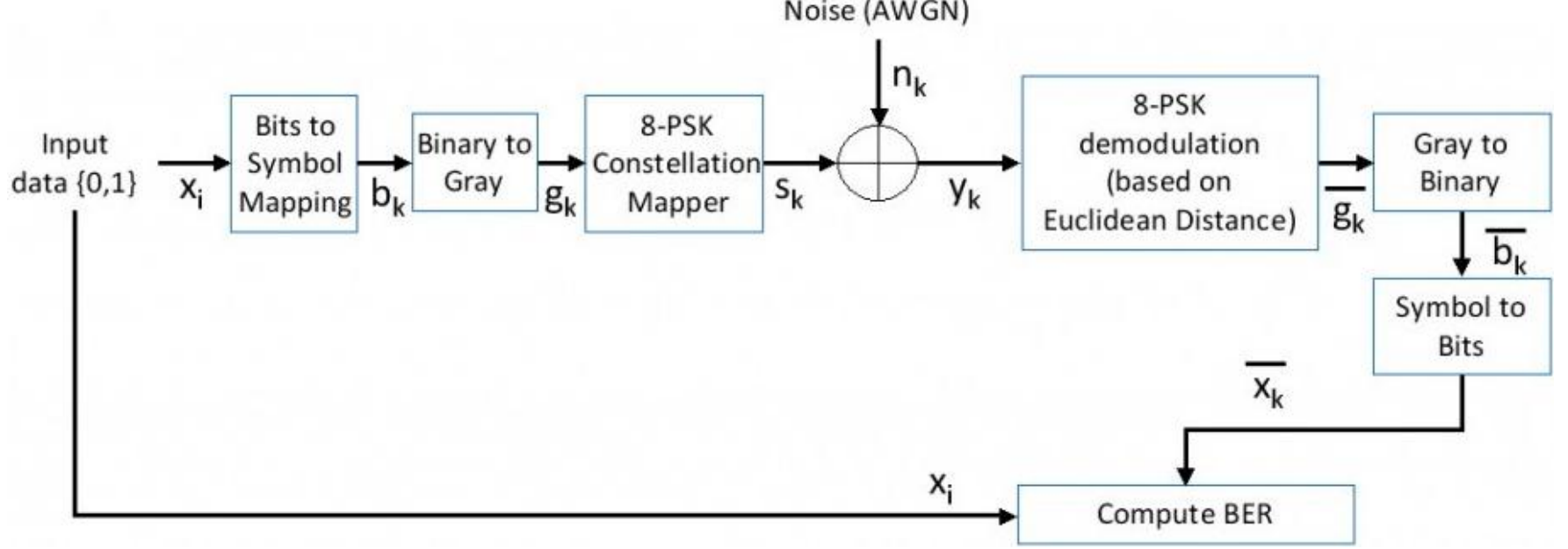

Figure 11: Block diagram of 8-PSK scheme

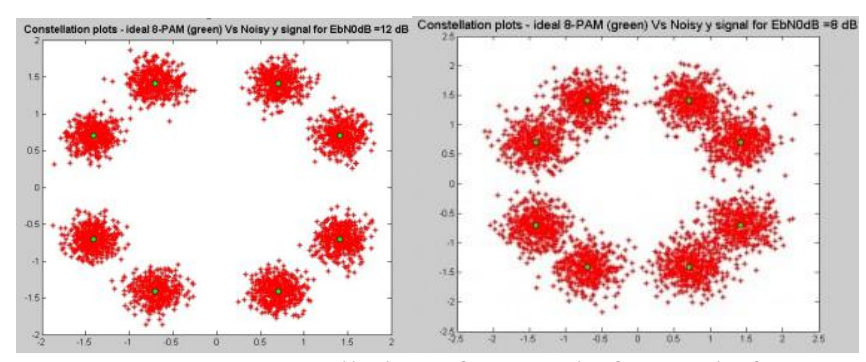

Figure 12: Constellation of 8-PSK before and after introducing noise

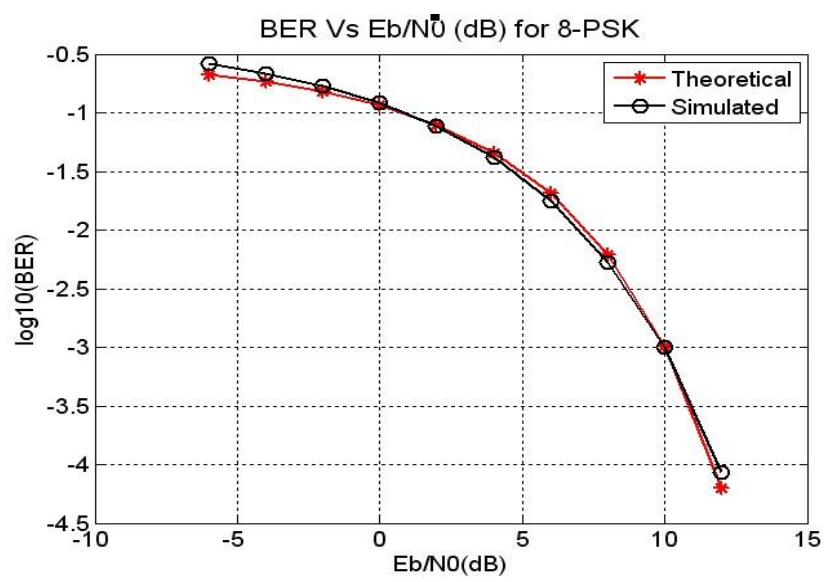

Figure 13: BER vs. Eb/No for 8-PSK

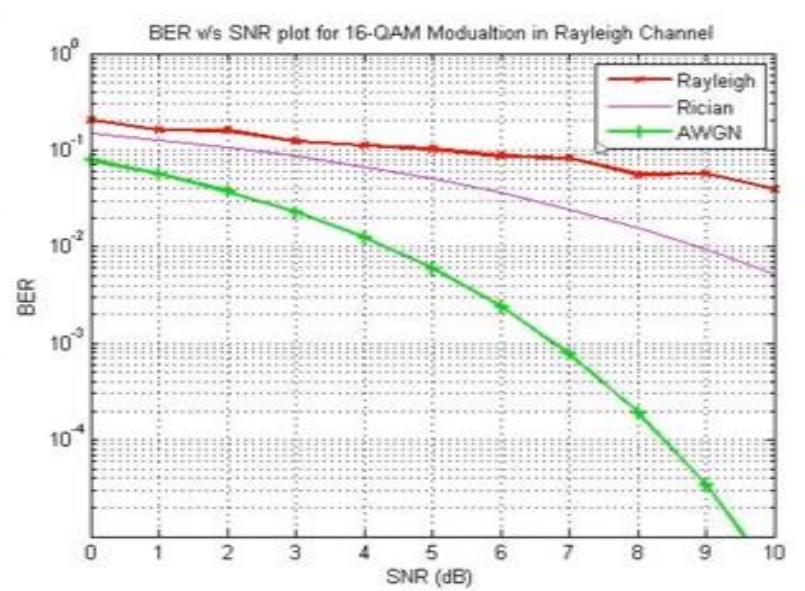

Figure 14: BER Vs. SNR plot for 16-QAM modulation in Rayleigh Channel

Volume 4 Issue 11, November 2015 


\section{International Journal of Science and Research (IJSR) \\ ISSN (Online): 2319-7064}

Index Copernicus Value (2013): 6.14 $\mid$ Impact Factor (2014): 5.611

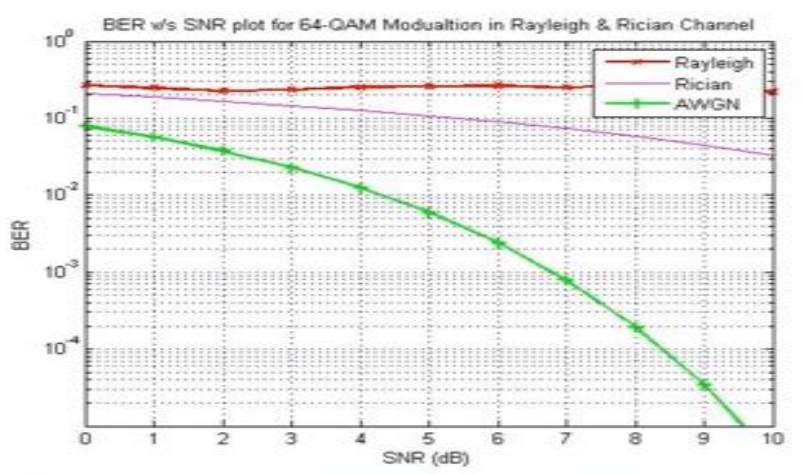

Figure 15: BER Vs. SNR plot for 64-QAM modulation in Rayleigh Channel

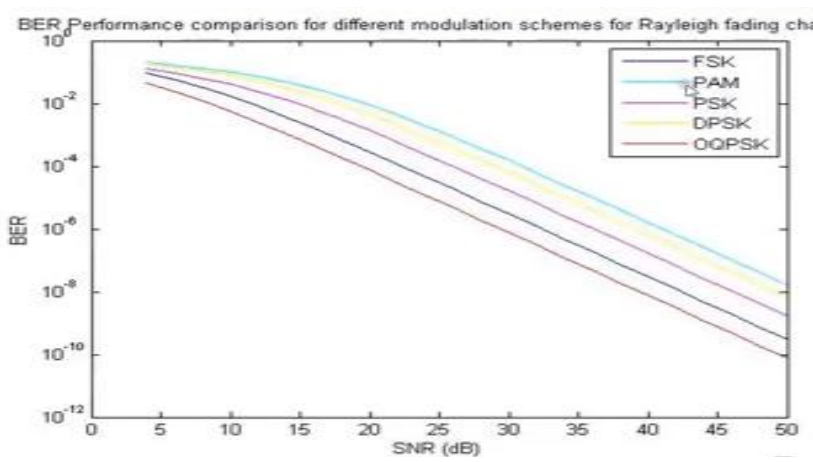

Figure 16: BER Performance comparison for different modulation schemes for Rayleigh fading channel

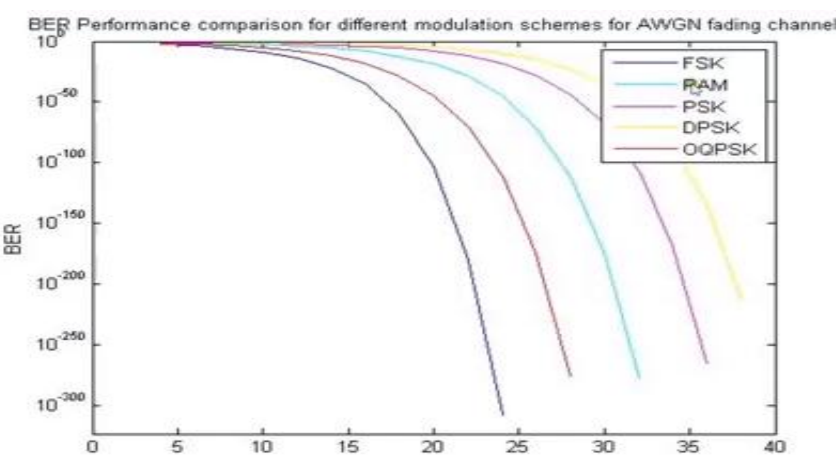

Figure 17: BER Performance comparison for different modulation schemes for AWGN fading channel

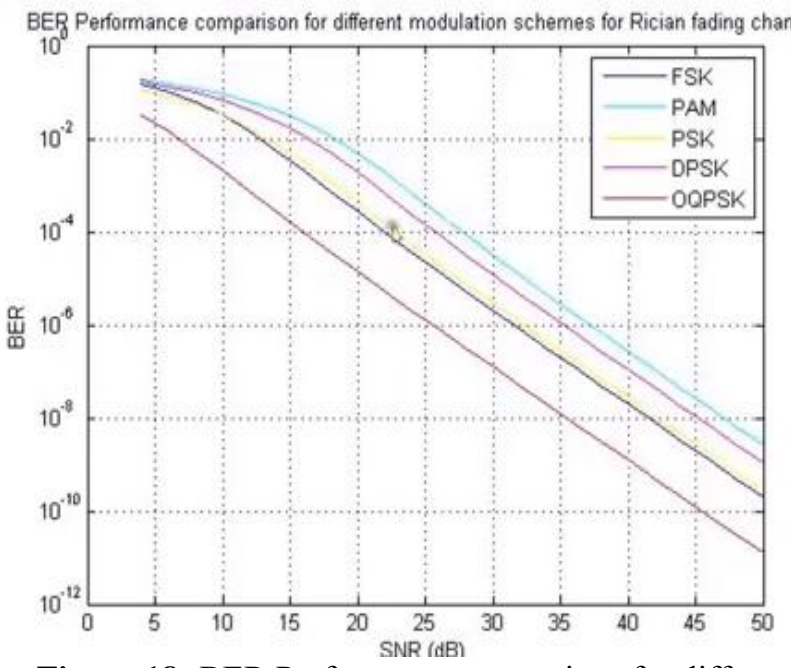

Figure 18: BER Performance comparison for different modulation schemes for Rican fading channel

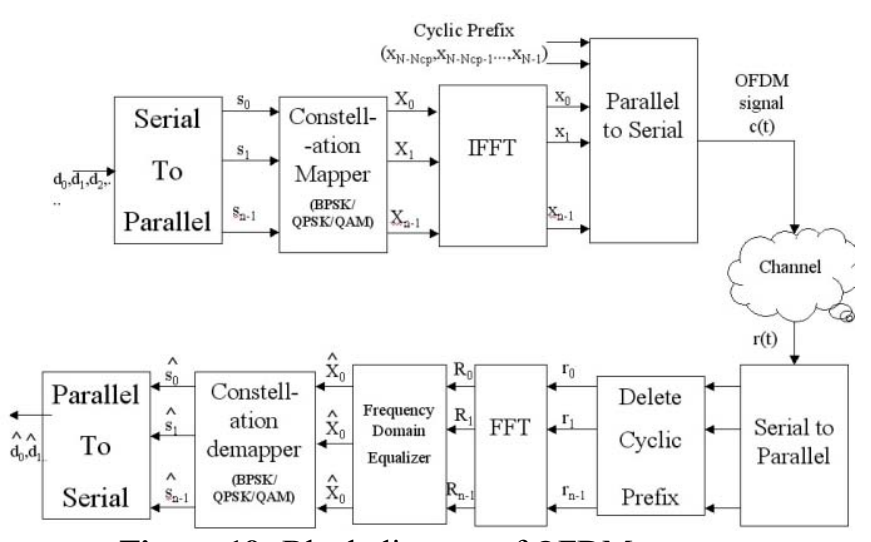

Figure 19: Block diagram of OFDM system

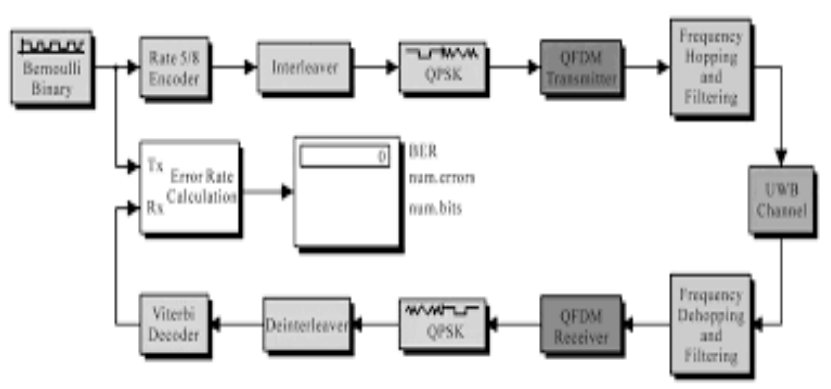

Figure 20: Block diagram of QPSK- OFDM system

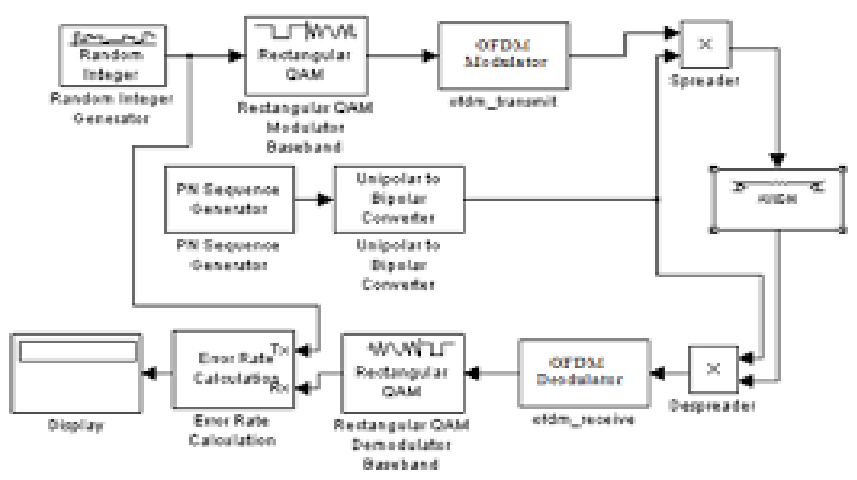

Figure 21: Block diagram of QAM-OFDM system in Simulink

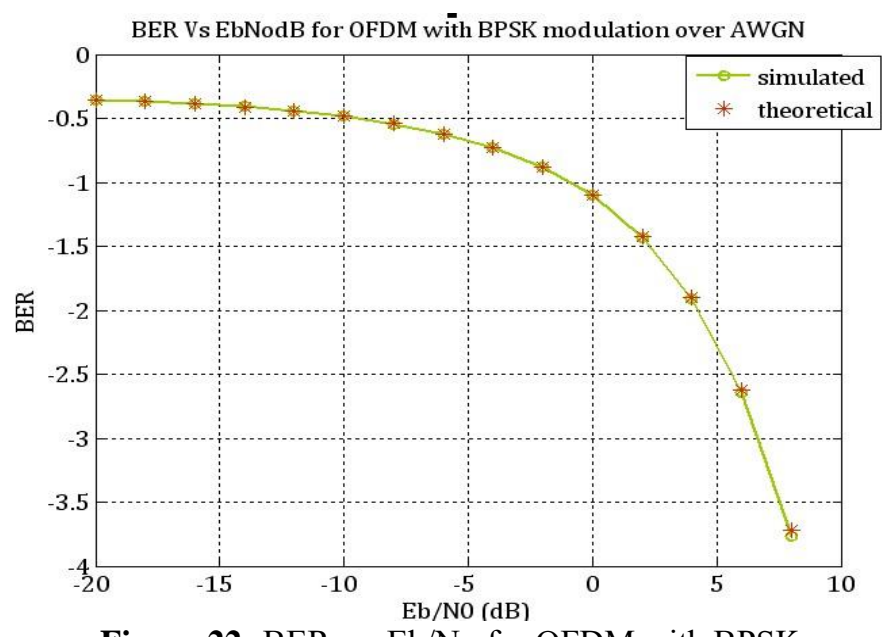

Figure 22: BER vs. Eb/No for OFDM with BPSK modulation over AWGN 


\section{International Journal of Science and Research (IJSR) \\ ISSN (Online): 2319-7064}

Index Copernicus Value (2013): 6.14 | Impact Factor (2014): 5.611

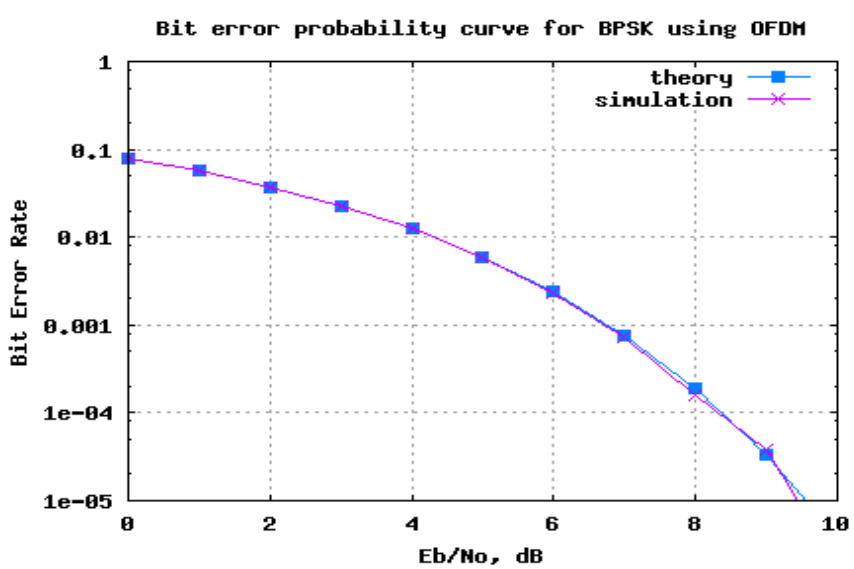

Figure 23: Bit error probability curve for BPSK using OFDM

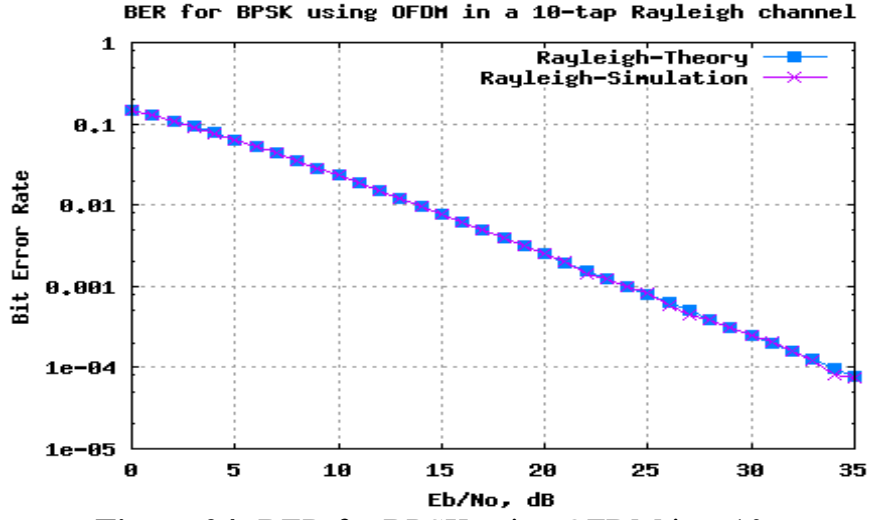

Figure 24: BER for BPSK using OFDM in a 10-tap Rayleigh channel

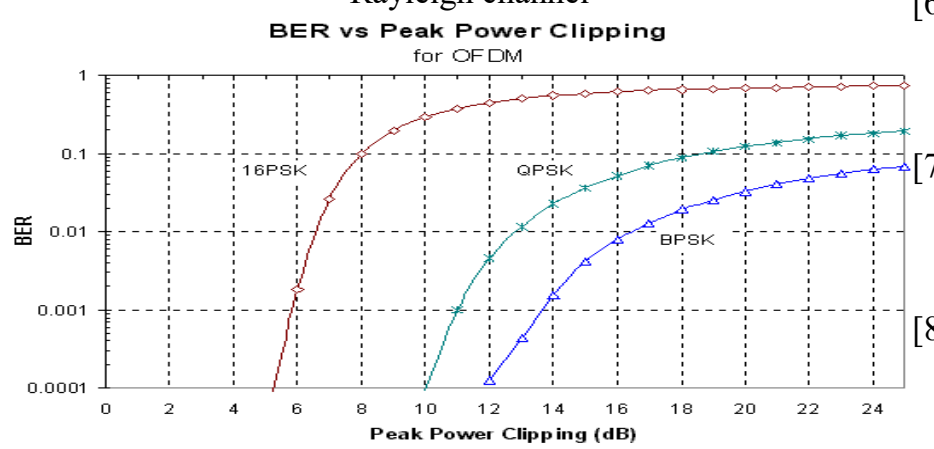

Figure 25: BER vs. Peak Power Clipping for OFDM

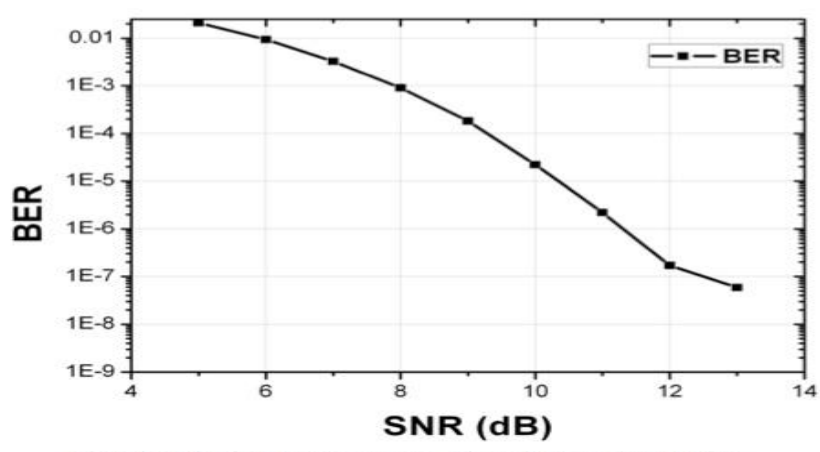

Simulated Bit Error Rate vs. Signal-to-Noise Ratio Modulation scheme DBPSK, data rate $2 \mathrm{Gbps}$

Figure 26: BER Vs. SNR plot for DBPSK modulation

\section{Conclusion}

BER performance for various digital modulation schemes were analyzed for AWGN, Rayleigh and rician fading channels. Selection of modulation schemes depends on performance characteristics. Choice comes with a trade of in hardware and performance. AWGN gives better performance when compare to other two fading channels. BPSK and OQPSK gives better performance, when compared to other modulation schemes. The multiple digital modulation schemes effective when paired with OFDM, like BPSK, QPSK, 8PSK, 16QAM, 32QAM, 32QAM, 64QAM, and it is more robust to noise and ISI.

\section{References}

[1] Panicker. V. Nitha, A kumar sukesh, "BER performance evaluation of different modulation schemes for AWGN and fading channel conditions", IJEAT, VOl3, June 2014.

[2] J. Proakis G., Digital Comms, $4^{\text {th }}$ edition, NY, MCGraw-Hill, 2001.

[3] F.B. Cockburn S.F. Fard. C. shhlegal and A. Ali mohammed, "Compact rician and Rayleigh fading simulation for random walk processes", issue 8, IET commas, 2009, vol3.

[4] Alouini and M.K. Simon, Digital modulation for various fading channels-An approach to analyze performance$1^{\text {st }}$ edition, Wiley 2000.

[5] S. Yi, Y. Li, T. Liangrui and W. Wenjin, "Adaptive resource allocation algorithm based on IEEE 802.16 OFDM", Seventh IEEE International Conference on Natural Computation, 2011.

[6] Mohamed A. Mohamed, Mohamed S. Abo-El-Seoud and Heba M. Abd-El-Atty, "Performance Simulation of IEEE 802.16e WiMAX Physical Layer" Seventh IEEE International Conference on Natural Computation, 2010

[7] R.B. Marks, K. Stanwood, D. Chang, et al. (October, 2004), IEEE Standard for Local and Metropolitan Area Networks, Part 16: Air Interface for Fixed Broadband Wireless Access Systems.

[8] Y. Byungwook, H. L. Kyu and L. Chungyong, "Implementation of IEEE 802.16e MIMO-OFDMA Systems with K-BEST Lattice Decoding Algorithm", International Conference on Consumer Electronics. Las Vegas, NV, USA, 2007.

[9] Pandey Ashish, Singh Sarala et.al, "Comparative Study of Different Modulation Technique in Chaotic Communication", International Journal of Scientific Research Engineering \& Technology (IJSRET), Volume 2, Issue 11, February 2014, pp 738-743.

[10] David Smith, Enginnering Computation with MATLAB, International 3 Edition, 2012.

[11] Upena Dalal, Wireless Communications, Oxford Higher Education, 2009.

\section{Author Profile}

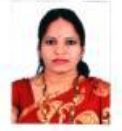

Usha S.M received the B.E. in Electronics and Communication Engineering from Mysore University in 2000 and M.Tech. Degree in VLSI Design and embedded system from the VTU Belgaum in 2011, presently pursuing Ph.D. in VTU Belgaum, Karnataka, India. 


\section{International Journal of Science and Research (IJSR) \\ ISSN (Online): 2319-7064 \\ Index Copernicus Value (2013): 6.14 | Impact Factor (2014): 5.611}

Currently working as an assistant professor in the dept. of electronics and Communication engineering at JSS ATE, Karnataka, India. Area of interest in VLSI and Communication. She is a member of MIE and ISTE.

Dr. K. R. Nataraj obtained his M.E degree from Bangalore University, India in 2000 and obtained his Ph.D degree from Dr. MGR University Chennai. He is currently working as professor and HoD for EC Dept of SJB Institute of Technology. His research interests are Wireless Communication, Microcontroller, Embedded system design and FPGA Implementation. He is a member of MIE, MISTE and IETE. 